\title{
Quality Investing and Pricing Strategies by Startups: Impacts of Demand Uncertainties and Capital Constraint
}

\author{
Bing Xia $\mathbb{D},{ }^{1,2}$ Richard Y. K. Fung, ${ }^{2}$ and Ju'e Guo $\mathbb{D}^{1}$ \\ ${ }^{1}$ School of Management, Xian Jiaotong University, Xian, Shaanxi 710049, China \\ ${ }^{2}$ Department of Systems Engineering \& Engineering Management, City University of Hong Kong, Tat Chee Avenue, \\ Kowloon, Hong Kong
}

Correspondence should be addressed to Ju'e Guo; guojue@mail.xjtu.edu.cn

Received 13 June 2018; Accepted 29 August 2018; Published 18 September 2018

Academic Editor: Alicia Cordero

Copyright (c) 2018 Bing Xia et al. This is an open access article distributed under the Creative Commons Attribution License, which permits unrestricted use, distribution, and reproduction in any medium, provided the original work is properly cited.

\begin{abstract}
Investing in product quality for future growths or conserving cash flow to avoid bankruptcy is an important trade-off faced by many capital-constrained startups. Focusing on the trade-off, this paper proposes a two-stage model where a startup firm must earn profit above the survival threshold by the end of every stage. Considering impacts of the uncertainty of demand responsiveness to quality (DRQ), market shocks, and survival threshold, a hedge with price setting and quality investing is established against the bankruptcy risk. Besides, this paper stresses the necessity of identifying the operational decisions of startups under both profit-seeking and survival-seeking objectives. Results illustrate that, under stochastic environment, the profit-seeking startup makes conservative (aggressive) investment on quality by setting lower (higher) price and investing in lower (higher) quality than the deterministic case, while the survival-seeking startup always sets its price linked to quality in positive direction. In addition, the profit-seeking startup always improves its investment on quality when either the mean or the variance of DRQ increase, while the survival-seeking startup reduces its investment when either the mean of DRQ increases to a certain level or the variance of DRQ increases. Other factors are also examined. Finally, this paper provides the startup managers some guidance on the quality investing strategy under capital constraints.
\end{abstract}

\section{Introduction}

According to the State Industrial and Commercial Bureau of China, over 16000 startups are formed every day in 2017; however, more than $30 \%$ of them have went bankrupt in just one year. In fact, most startups fail, with only a small proportion of these firms showing continued growth and launching initial public offerings [1]. Startups are endowed with unique characteristics regarding their asset structure, organization type, and growth orientation [2], and their operational decisions are often restricted by debt and other financial considerations [3]. For example, due to the immature financial market (a common characteristic of emerging markets like China), it is very difficult for those startups in China to borrow cash from outside to hedge the risk of default. Hence, the threat of startups' default is an exigent consideration in emerging markets. Startups that take on debt may face immediate bankruptcy once payback default happens [4]. They always exploit some immediate business opportunities for producing enough short-term cash flows, so as to keep up with the cash outflows and avoid bankruptcy [5].

1.1. Challenges of Quality Investing. Besides the short-term survival, startups also seek opportunities for long-term growth. Commonly, two ways are adopted to establish the foundation for future development: investing in process development to reduce the production cost or investing in its unique product features to make their products attractive. However, even in settings where it gains initial competitive advantage by low production cost, many startups have to develop unique features to build their brands and hold stable market shares. Actually, among most crucial issues of product features, quality has emerged as a vital strategy since 1990s [6].

It is indicated in the entrepreneurship literature that investing in long-term growth and creating short-term profits 
are intimately linked [4, 7]. Referring to the investment on quality, a fundamental trade-off is focused on in this paper: whether to invest in product quality that can improve market share and increase future revenue, or conserve cash flow in the current stage and avoid bankruptcy.

1.2. Demand Uncertainties. Firms may face considerable uncertainties when introducing new products, especially uncertainties with regard to the demand responsiveness to quality (DRQ) and market shocks. Referring to these demand uncertainties, firms always make a lot of market researches.

These uncertainties are crucial because most upfront investments in high quality may be wasted when consumers show little interest in products or when the realized market size is small. Once the quality investing decision is made, a large amount of its short-term cash reserves are consumed and the positioned quality is hard to change in the short run owing to high repositioning costs. Thus, startups would face the bankruptcy risk in the short term should the demand be lower than expected. Actually, based on the study of insights [8], top two reasons why startups fail are "no market need" and "running out of cash." For example, Tesla has taken a leadership role in the quality of electric motorcars but nearly failed in 2008 for its large investments on latest technologies. It finally goes through the risk, mainly because its cars have attracted most target consumers who are willing to pay for greenness [9].

1.3. Modeling Bankruptcy Risk, Opportunity, and Managerial Guidance. Operational risks are sometimes measured by the profit loss generated by the firm's ordinary activities [10]. However, this method does not fit the startups since the profit loss may cause bankruptcy to them. Given deterministic environment, the startup must maximize its profit to meet the survival threshold. In other words, all bankruptcy risks in the startup's operational decisions come from the uncertainty of DRQ and market shocks. Thus, this paper takes the survival probability as a relevant measure of the risks in the experimental design.

An ample amount of empirical evidence refers to the balance between quality innovation and survival chance (as illustrated in the literature review); however, few researches use modeling framework. This has motivated our efforts to model the trade-off with demand uncertainties and compare the operational decisions against the bankruptcy risk under both survival-seeking and profit-seeking objectives.

The model specification and analysis are divided into three steps. In the first step, a basic two-stage model under deterministic environment is analyzed. Some analytical tractable thresholds of the operational decisions are derived and taken as benchmarks. In the second step, discussions are extended by introducing the uncertainty of DRQ and market shocks sequentially. In the third step, computational analysis is made to support the obtained propositions and make the comparisons between different objectives intuitive.

Based on the analysis, this paper provides the startup managers with three guidelines on price setting and quality investing decisions under capital constraints. First, this paper specifies survival probability as a measurement of the bankruptcy risk exposed in the operational decisions and identifies some important parameters related to the risks. Second, when faced with demand uncertainties and the consequent probabilistic survival constraint, this paper provides useful hedges with price setting and quality investing strategies against the bankruptcy risk. Third, to obtain an overall knowledge of startups' quality investing decisions for managers, we emphasize the importance of identifying the operational objectives.

This paper is organized as follows. Section 2 reviews the related literature. Section 3 constructs the basic models. Section 4 performs the analytical analysis, and Section 5 provides computational analysis. Section 6 concludes the paper.

\section{Literature Review}

Three streams of literature related to our work are provided, namely, startup product innovation, quality investing strategies, and entrepreneurial behaviors under capital constraint.

2.1. Startup Product Innovation. Quality improvement is a crucial issue of product innovation which aims to attract consumers and enhance the market share. Some literature sources of product innovation consider startups to be innovative and able to introduce a creative destruction. Kim et al. [11] find that small manufacturing enterprises (SME) are more likely to survive over a longer period of time by creating and marketing quality products appealing to the customer. Cefis and Marsili $[12,13]$ also argue that by being innovative, firms greatly increase their survival chances. Criscuolo et al. [14] report that being a startup in the service industry increases the likelihood of a firm to make product innovation. By contrast, Shane [15] argues that most startups begin in "pretty mundane, run-of-the-mill industries" and are not particularly innovative. Bhidé [7] points out that only $6 \%$ of Inc. 100 founders claim to have begun their firms with unique products or services, while $58 \%$ of these founders offer identical or close substitutes to existing products or services. As a supplement to these existing empirical studies, this paper uses analytical frameworks to study startup's quality investing decisions and provides an analytical explanation to the performance of startups' product innovation.

2.2. Quality Investing Strategies. The quality investing strategy of a firm has been examined in many fields, such as economics, marketing, and operations management $[6,16-$ 18]. It is shown in literature that decisions on quality investing are closely related to roles that quality plays in product differentiation, in coordinating supply chains, in making inventory and capacity decisions, and so on.

In operation management literature, Banker et al. [6] assume consumer demand as a linear function of price and quality level selected by the entering firm. They develop formal oligopolistic competition models to investigate whether equilibrium qualities increase as the competition intensifies. Based on their assumption, some extensions are made: Xie et al. [19] investigate the quality investing and the price setting decision of a make-to-order supply chain with uncertain 


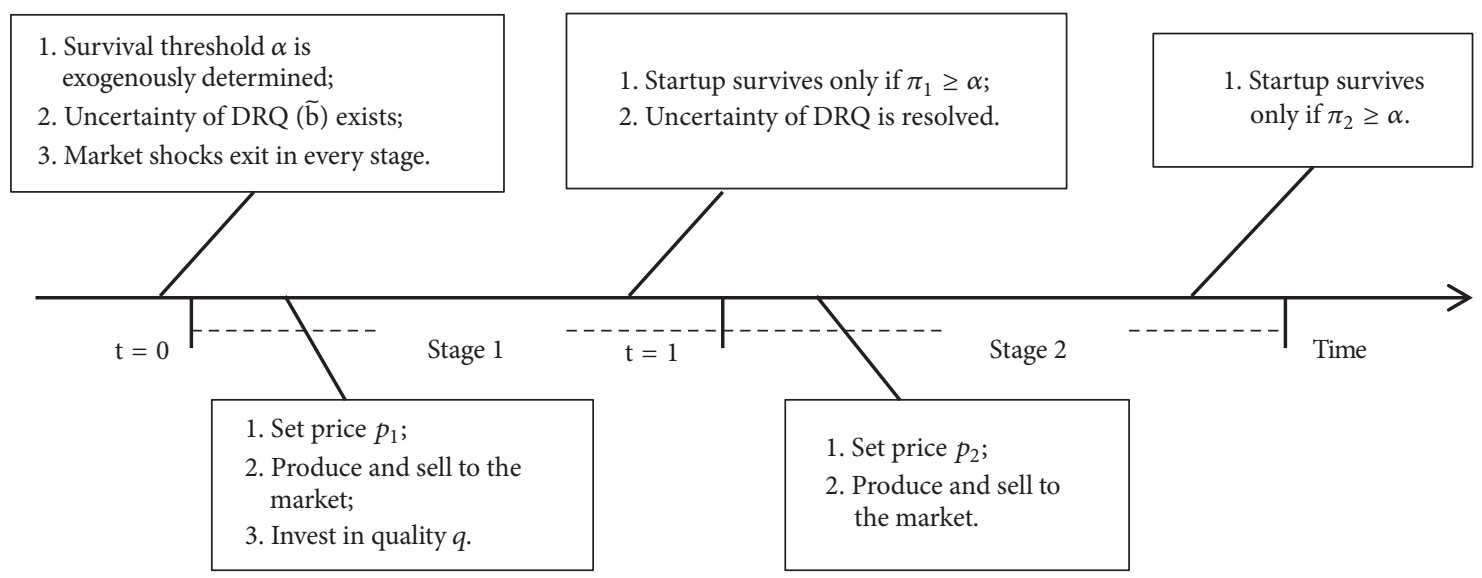

FIgURE 1: Sequence of events and decisions of the startup in a two-stage model.

demand in the international trade; Karaer and Erhun [20] study the role of quality in entry deterrence by considering a scenario of potential entry into a monopoly market; Zhang and Hong [21] consider the manufacturer's R\&D investment strategy and pricing decisions in a decentralized supply chain and propose a profit sharing policy to coordinate the decentralized supply chain; Li et al. [22] incorporate the bargaining power into the product quality and pricing decisions in a two-echelon supply chain, where the supplier offers core components to the manufacturer. It is found that the above-mentioned literature sources do not address the startup's concerns and capital conditions. This paper adopts the same assumption used by Banker et al. [6] and treats the quality investing decision as a "demand-enhancing effort" in a non-address product differentiation model. Based on the model, we address a gap in this line of literature by (i) focusing on startups' quality investing strategies under capital constraint, (ii) considering the delay between the quality investing and the demand enhancement, and (iii) examining impacts of demand factors on the operational decisions.

\subsection{Entrepreneurial Behaviors under Capital Constraint.} According to enterprises' market-entry behaviors, conventional wisdoms state that enterprises pursue profits in both short and long terms. However, firms' profit-seeking behavior may be restricted by capital constraints $[23,24]$, especially for startups. A lot of literature sources have investigated decision models that involve the financing and operations of startups [5, 25-27]. Tanrisever et al. [5] propose a profit-seeking framework for the startup under a survival constraint and examine the allocation of process investment and production. They find that debt constraint shrinks the decision space for these firms. However, most recent researches argue that the survival-seeking objective is more suitable for the startup.

Babich [28] finds that a firm that can stay or survive in business has a higher probability to earn profit in the long term. Therefore, startups may tend to seek survival rather than profit in new markets. Then, the objective of a startup should take into account the acute failure risk associated with entry into a new market. Thus, most recent studies assume that a survival-seeking startup maximizes its survival probability [27, 29-31].

Based on this assumption, Archibald et al. [29] argue that startups may adopt conservative strategies in making inventory policies, while Swinney et al. [27] find that startups perform aggressively in capacity investment. Xia et al. [31] find that startups also perform aggressively in the quality competition with established firms. Finally, Levesque et al. [32] compare a survival-maximizing startup with a profitmaximizing startup, and they find that if the market-entry investment is large, the former produces at a larger scale than the latter when the startup competes with an established rival, which in turn is forced to reduce its production level. We build on these ideas and make contributions to the literature stream by the following: (i) We consider both profit- and survival-seeking frameworks for quality investing decisions of the capital-constrained startup. (ii) We illustrate how price setting and quality investing strategies combine as a hedge against the operational risk, showing how the hedges vary under different objectives. Besides, different from the conventional one-stage comparisons, (iii) a two-stage model is established in this paper and the startup must consider its objective over two stages jointly. That is, the cash flow taken up in the current stage for quality improvement leads to future profits for the profit-seeking startup, while leading to future survival chances for the survival-seeking startup.

\section{The Model}

Consider a two-stage model where a risk-neutral monopoly startup serves the market. In the first stage, the firm borrows cash and starts the production from a common product. After obtaining the revenue, it invests in quality innovation for the production of the next stage. In the second stage, the startup adjusts its price setting according to the improved product. By the end of every stage, the startup must reach a survival threshold (minimum profit level) denoted by $\alpha$. Figure 1 illustrates the sequence of events and the startup's decisions. Let $p_{i}, d_{i}, c_{i}, q_{i}$, and $\pi_{i}$ denote the price, demand, unit cost, quality, and profits in stage $i(i=1,2)$, respectively. (For simplicity, this paper follows the two-stage model 
setting adopted by Tanrisever et al. [5] and Wei et al. [30] and assumes that operational decisions of both stages are relatively independent. Moreover, the reserved profit in the first stage cannot be left to the second stage and affect the cash flow and survival probability in the second stage. In fact, there is a long development cycle for the quality innovation. Besides the investment on quality, a new entrant always exploits all early profits to market survey, capacity investment, new recruitments, and so on.) For simplification, the unit cost is assumed to be constant in every stage.

Following the definition of Banker, Khosla, and Sinha [6], impacts of price and quality on demand are denoted as $d_{i}=\theta-a p_{i}+\widetilde{b} q_{i}$, where $a$ and $\widetilde{b}$ (a random variable) describe the demand responsiveness to price and quality. (The basic model of Banker, Khosla, and Sinha [6] is used to study the quality competition between duopoly firms. In the monopoly market, the startup enjoys the whole intrinsic demand potential, and demand function is only affected by its own price and quality. This demand function is supported by many researches $[20,33-35]$.). Given that the initial quality $q_{1}$ is constant in the model, it can be assumed that $q_{1}=0$ and the initial demand can be simplified into $d_{1}=\theta-a p_{1}$, while the demand in the second stage can be denoted as $d_{2}=$ $\theta-a p_{2}+\tilde{b} q$. To achieve quality improvement $q$, the startup incurs the corresponding investment cost $k q^{2}$. (This paper adopts a commonly used quadratic form; i.e., improving the quality has an increasing incremental cost at high levels, which yields a diminishing return on the quality expenditure. This relationship is commonly observed in the extant literature $[6,20,33-35]$. Thus, cost coefficient $\mathrm{k}$ is a positive scale parameter, which measures the complexity of the quality development.)

Furthermore, this paper provides three important assumptions.

Assumption 1. For one unit of improved quality, the market share increases by a random amount $\widetilde{b}$. It has a known distribution function, $\psi(\widetilde{b})$, with mean $b$, and variance $\sigma^{2}$. It is resolved by market research before the second stage.

Startups frequently face considerable uncertainties of demand conditions when they make quality investing decisions. One of the most crucial uncertainties is the consumers' responsiveness to the improved quality. There are a lot of failures in the business history due to consumers' tastes. Some improved products were thought to be good ideas but turned out to be unattractive, e.g., New Coke, Facebook Home, and AirPods. It should be noted that the consequent market failure cannot be easily prevented by other marketing strategies such as price adjustment. Therefore, firms always spend millions of dollars on marketing surveys to resolve the uncertainty of DRQ.

Assumption 2. $\alpha$ is the survival threshold and is exogenously set before each stage.

This assumption is supported by some important facts about the capital constraints of the startup. First, weak financial structure is a well-known weakness of startups. This leads to a high dependency from short-term bank loans as a predominant source of external financing. Supported by these bank loans, some overhead expenses for staff recruiting and land renting are incurred before production and investment. These expenses are exogenously set before each stage and must be paid after the startup generates revenue. Otherwise, the startup may be forced to quit the industry [29]. Second, considering that the startup may borrow money from the market in multiple rounds for production and investment, a certain level of profit becomes an important measurement for the bank or VC to determine whether to lend the startup in the next round. As a target profit, $\alpha$ is influenced by many factors, such as competition, wage rate, and economy of scale [30]. This variable varies across different stages and startups. For simplification, $\alpha$ is assumed constant in our model.

Assumption 3. Under the profit-seeking objective, the startup optimizes its utility by maximizing the profits in two stages: $U=U_{1}+\operatorname{Pr}\left(\pi_{1} \geq \alpha\right) * U_{2}$, where $U_{i}=E\left(\pi_{i}\right)$. In contrast, under the survival-seeking objective, it maximizes the survival probabilities in two stages: $U=U_{1} * U_{2}$, where $U_{i}=\max \left[\operatorname{Pr}\left(\pi_{i} \geq \alpha\right)\right]$.

This model setup is supported by Wei, Yao, Jiang, and Young [30]. It should be noted that, under the profit-seeking objective, the startup mainly focuses on the expected profit in every stage. The survival constraint is crucial mainly because it affects startup's entrance into the second stage and does not affect the decision making in the second stage.

\section{Analytical Analysis}

The analysis will start from the basic model under deterministic environment. Then, the uncertainty of DRQ and market shocks are introduced into the model sequentially.

4.1. Deterministic Environment. Under the deterministic environment, there is no bankruptcy risk in the startup's operational decisions, because they can always reserve enough cash flow for the survival threshold. Under both objectives, the startup only needs to maximize the profits in every stage.

Here, given $\widetilde{b}=b$, the benchmark model is described as follows:

$$
\begin{aligned}
& \pi^{*}=\max _{p_{1}, q \geq 0}\left(p_{1}-c\right)\left(\theta-a p_{1}\right)-k q^{2}+\pi_{2}(q, b), \\
& \text { s.t. }\left(p_{1}-c\right)\left(\theta-a p_{1}\right)-k q^{2} \geq \alpha, \\
& \text { where } \pi_{2}(q, b)=\max _{p_{2} \geq 0}\left(p_{2}-c\right)\left(\theta-a p_{2}+b q\right) .
\end{aligned}
$$

Inequality (2) indicates that the startup can survive through the first stage only if its profit $\pi_{1}$ exceeds the threshold $\alpha$. Optimal operational decisions and profits under the deterministic environment are characterized in Proposition 4. Proofs of propositions can be seen in the appendix.

Proposition 4. Under the deterministic environment, both the profit-seeking and the survival-seeking startups will maximize 
their profits by setting price $p_{1}^{*}=p_{m}=(\theta+a c) /(2 a)$. Then, the optimal quality $q^{*}$ and the consequent expected profit $\pi^{*}$ are determined as follows:

$$
\begin{aligned}
& q^{*}= \begin{cases}q_{n} & \text { if } \Delta_{0} \leq 0 \text { and } 4 a k>b^{2} \\
q_{m} & \frac{o}{w}\end{cases} \\
& \pi^{*} \\
& = \begin{cases}\frac{(\theta-a c)^{2}}{4 a}+\frac{k(\theta-a c)^{2}}{4 a k-b^{2}} & \text { if } \Delta_{0} \leq 0 \text { and } 4 a k>b^{2} \\
\frac{\left(\theta-a c+b q_{m}\right)^{2}}{4 a} & \frac{o}{w} .\end{cases}
\end{aligned}
$$

Here $q_{n}=b(\theta-a c) /\left(4 a k-b^{2}\right)$ is the quality maximizing the overall profit without capital constraint, $q_{m}=$ $\sqrt{(1 / k)\left((\theta-a c)^{2} / 4 a-\alpha\right)}$ is the maximum quality in which the capital constraint is binding, and $\Delta_{0}=\alpha-\left((\theta-a c)^{2} \cdot\left(16 a^{2} k^{2}-\right.\right.$ $\left.\left.12 k a b^{2}+b^{4}\right)\right) / 4 a\left(4 a k-b^{2}\right)^{2}$.

As the profit function is concave on the price, the startup can earn the largest profit by setting the price $p_{m}$ and consequently obtain the largest profit in the first stage, $\pi_{1}^{*}=$ $(\theta-a c)^{2} / 4 a$.

Note that $\Delta_{0} \geq 0 \Longleftrightarrow q_{m} \leq q_{n}$. When $\Delta_{0} \leq 0$, quality improvement is not attractive enough and the startup can get the largest profit $\pi^{*}$ by positioning a small $q_{n}$, which can be supported by the surplus profit $\left((\theta-a c)^{2} / 4 a-\alpha\right)$.
However, when $\Delta_{0} \geq 0$, quality improvement is so attractive that the startup keeps enhancing the investment until the surplus profit is run out. Then, it will invest in the maximum quality $q_{m}$. Thus, the increase of $\Delta_{0}$ represents the startup's willingness to invest in quality. Based on the sensitivity analysis of $\Delta_{0}$, it can be found that the startup is more willing to invest if the consumers have a high responsiveness to the improved quality ( $b$ increases). In contrast, the startup reduces its investment if the quality development becomes more difficult ( $\mathrm{k}$ increases) or the original market size becomes larger ( $\theta$ increases). The startup will also reduce its investment if the variable cost $c$ or survival threshold $\alpha$ increase, because it must allocate more cash flow for the production and debt repayment.

4.2. Uncertainty of $D R Q$. Compared to the deterministic environment, introduction of the uncertainty of DRQ brings operational risk to the second stage, while the environment in the first stage is still deterministic. On the one hand, a survival-seeking startup absolutely maximizes its profit in the first stage and allocates all its surplus profit into the investment on quality, $q_{m}$. On the other hand, the profitseeking case deserves a further study.

The following proposition characterizes the optimal price and quality decisions of the profit-seeking startup with only the uncertainty of $\tilde{b}$ :

Proposition 5. When the DRQ is stochastic, the profit-seeking startup's optimal price is $p_{1}^{*}=(\theta+a c) /(2 a)$. In addition, the optimal quality and maximized profits for the startup are given by

$$
\begin{aligned}
& q^{*}= \begin{cases}q_{u n} & \text { if } \Delta_{u b} \leq 0 \text { and } 4 a k>b^{2}+\sigma^{2} \\
q_{m} \quad \frac{o}{w},\end{cases} \\
& \pi_{u b}^{*}= \begin{cases}\frac{(\theta-a c)^{2}}{4 a}+\frac{\left(4 a k-\sigma^{2}\right)(\theta-a c)^{2}}{4 a\left(4 a k-b^{2}-\sigma^{2}\right)} & \text { if } \Delta_{u b} \leq 0 \text { and } 4 a k>b^{2}+\sigma^{2} \\
\frac{(\theta-a c)^{2}+\left(b^{2}+\sigma^{2}\right) q_{m}^{2}+2 b(\theta-a c) q_{m}}{4 a} & \frac{o}{w} .\end{cases}
\end{aligned}
$$

Here, $q_{u n}=b(\theta-a c) /\left(4 a k-b^{2}-\sigma^{2}\right)$ is the quality which maximizes the overall profit without capital constraint under the uncertainty of DRQ, and $\Delta_{u b}=\alpha-\left((\theta-a c)^{2} \cdot\left(16 a^{2} k^{2}-\right.\right.$ $\left.\left.12 k a b^{2}-8 a k \sigma^{2}+b^{4}+2 b^{2} \sigma^{2}+\sigma^{4}\right)\right) / 4 a\left(4 a k-b^{2}-\sigma^{2}\right)^{2}$.

As $\Delta_{u b} \geq 0 \Longleftrightarrow q_{u n} \geq q_{m}$, the increase of $\Delta_{u b}$ represents the willingness to invest more on quality improvement. The startup will invest all surplus profit if $\Delta_{u b}>0$. Proposition 5 shows that $\Delta_{u b}-\Delta_{0}=\left(k b^{2} \alpha^{2} \cdot\left(8 a k-2 b^{2}-\right.\right.$ $\left.\left.\sigma^{2}\right)\right) /\left(4 a k-b^{2}\right)^{2}\left(4 a k-b^{2}-\sigma^{2}\right)^{2}>0$ and $\mathrm{q}_{u n}-\mathrm{q}_{n}>0$, which means that under the uncertainty of DRQ, the most profitable quality value without capital constraint becomes higher and the probability of investing all surplus profit becomes larger. Moreover, it can be proved that $\pi_{u b}^{*}$ is always larger than $\pi_{0}^{*}$. Therefore, the uncertainty of DRQ makes quality improvement a more attractive option to the profitseeking startup.

In a word, the survival-seeking startup must invest all surplus profit on quality improvement, and the profit-seeking startup will invest all surplus profit with more variable DRQ. The uncertainty of DRQ encourages the startup under both objectives to place more attention on future growth.

4.3. Market Shocks. In this part, besides the uncertainty of DRQ, market shocks are also taken into consideration. Market shocks, $\widetilde{\varepsilon}_{t}$, exist at the beginning of each stage $\mathrm{t}$ $(\mathrm{t}=1,2)$ with mean 0 , variance $v^{2}$, density function $\omega(\cdot)$, and cumulative distribution $\vartheta(\cdot)$. It is assumed that market 
shocks in different stages are independent and they follow the symmetrical distribution. Both market shocks are realized at the end of each period.

Profit-Seeking Case. A profit-seeking startup optimizes its utility by maximizing the expected profits in both stages:

$$
\begin{aligned}
& \begin{array}{l}
U^{*} \\
=\max _{p_{1}, q \geq 0} E_{\widetilde{\varepsilon}_{1}}\left\{\left(p_{1}-c\right)\left(\theta+\widetilde{\varepsilon}_{1}-a p_{1}\right)-k q^{2}\right\} \\
\quad+E_{\widetilde{\varepsilon}_{1}, \widetilde{b}_{2}} \pi_{2}\left(q ; \widetilde{\varepsilon_{1}}, \widetilde{b}\right),
\end{array} \\
& \text { Where } \pi_{2}\left(q ; \widetilde{\varepsilon}_{1}, \widetilde{b}\right) \\
& \quad=\max _{p_{2} \geq 0} E_{\widetilde{\varepsilon}_{2}}\left\{\left(p_{2}-c\right)\left(\theta+\widetilde{\varepsilon}_{2}+\tilde{b} q-a p_{2}\right)\right\} . \\
& \text { s.t. } \pi_{1}\left(\widetilde{\varepsilon}_{1}\right)-\alpha \geq 0 .
\end{aligned}
$$

Further, the problem can be formulated as follows:

$$
\begin{aligned}
\pi^{*}= & \max _{p_{1}, q \geq 0} E_{\widetilde{\varepsilon}_{1}}\left\{\left(p_{1}-c\right)\left(\theta+\widetilde{\varepsilon}_{1}-a p_{1}\right)-k q^{2}\right\} \\
& +E_{\widetilde{\varepsilon}_{1}, \widetilde{b}}\left\{\frac{(\theta+\widetilde{b} q-a c)^{2}}{4 a} \mid \pi_{1}\left(\widetilde{\varepsilon}_{1}\right) \geq \alpha\right\} .
\end{aligned}
$$

If $\mathrm{p}^{*}$ and $\mathrm{q}^{*}$ denote the optimal price and quality for the startup in the first stage, for the profit-seeking case, we have the following proposition.

Proposition 6. Compared with the deterministic environment, given both the uncertainty of DRQ and market shocks, if the startup improves (reduces) its investment on quality (i.e., $\left.q^{*} \geq q_{m}\left(q^{*} \leq q_{m}\right)\right)$, it will also increase (decrease) its price setting (i.e., $\left.p^{*} \geq p_{m}\left(p^{*} \leq p_{m}\right)\right)$ to avoid the bankruptcy risk.

Actually, as the survival probability in the first stage is $\mathrm{F}\left(\pi_{1}-\alpha \geq 0\right)=1-\vartheta_{\widetilde{\varepsilon}_{1}}\left(\left(k q^{2}+\alpha\right) /(p-c)+a p-\theta\right)$, it can be found that the survival probability in the deterministic environment $\left(p_{m}, q_{m}\right)$ is exactly 0.5 if the market shock has a symmetrical probability density function (e.g., normal and uniform), Therefore, the operational decision in the deterministic case $\left(p_{m}, q_{m}\right)$ can serve as a benchmark for the adjustment of operational decisions in the stochastic environment. The startup survives with a probability of less (more) than 0.5 if $q^{*} \geq q_{m}\left(q^{*} \leq q_{m}\right)$ and $p^{*} \geq p_{m}\left(p^{*} \leq\right.$ $\left.p_{m}\right)$. Obviously, the risk of operational decisions increases if the survival probability decreases. Therefore, the operational decisions can be regarded as aggressive (conservative) only if the survival probability is smaller (larger) than 0.5 .

Proposition 6 provides a hedge with price setting and quality investing strategies against the bankruptcy risk. If the startup finds the investment on quality attractive, it will increase its investment aggressively $q^{*} \geq q_{m}$. At the same time, it will increase the price to catch the probability that the market shock is a positive value $p^{*} \geq p_{m}$, creating enough cash flow for the investment on quality. Of course, larger bankruptcy risk comes with these aggressive decisions. In contrast, if the startup finds the consumers not willing to pay for the quality improvement, it invests conservatively in quality $q^{*} \leq q_{m}$ and decreases the price $p^{*} \leq p_{m}$ in case the market shock is a negative value. With these conservative decisions, survival chance must become larger.

Survival-Seeking Case. The survival-seeking startup optimizes its utility by maximizing the overall survival probability:

$$
\begin{aligned}
& U^{*}=\max _{p_{1}, q \geq 0} \operatorname{Pr}_{\widetilde{\varepsilon}_{1}}\left\{\left(p_{1}-c\right)\left(\theta+\widetilde{\varepsilon}_{1}-a p_{1}\right)-k q^{2} \geq \alpha\right\} \\
& * \operatorname{Pr}_{\widetilde{\varepsilon}_{1}, \widetilde{b}}\left\{\pi_{2}\left(q ; \widetilde{\varepsilon}_{1}, \widetilde{b}\right) \geq \alpha\right\}, \\
& \text { Where } \pi_{2}\left(q ; \widetilde{\varepsilon}_{1}, \tilde{b}\right) \\
& =\max _{p_{2} \geq 0} \operatorname{Pr}_{\widetilde{\varepsilon}_{2}}\left\{\left(p_{2}-c\right)\left(\theta+\widetilde{\varepsilon}_{2}+\tilde{b} q-a p_{2}\right) \geq \alpha\right\} .
\end{aligned}
$$

Considering that the uncertainty of DRQ is resolved before the second stage, the startup only faces market shock when setting the price in the second stage, $p_{2}^{*}=$ $\operatorname{argmax}_{p_{2} \geq 0} \operatorname{Pr}\left\{\left(p_{2}-c\right)\left(\theta+\widetilde{\varepsilon}_{2}-a p_{2}+\tilde{b} q\right) \geq \alpha\right\}=$ $\operatorname{argmax}_{p_{2} \geq 0} \operatorname{Pr}\left\{\widetilde{\varepsilon}_{2} \geq \alpha /\left(p_{2}-c\right)+a p_{2}-\theta-\tilde{b} q\right\}=c+$ $(\alpha / a)^{1 / 2}$. Thus, the survival probability in the second stage is $1-\mathrm{F}\left(\widetilde{\varepsilon}_{2}+\widetilde{b} q \geq 2 \sqrt{a \alpha}+\mathrm{ac}-\theta\right)$. It is assumed that $\epsilon=\widetilde{\varepsilon}_{2}+\widetilde{b} q$ and the probability density function, $\kappa(\epsilon)$, follows a cumulative distribution $\phi(\epsilon)$ with mean $b q$ and variance $v^{2}+q^{2} \sigma^{2}$. Therefore, the survival probability in the second stage can be simplified as $1-\phi(2 \sqrt{a \alpha}+a c-\theta)$.

Besides, the expression of the first stage can also be transformed: $U_{1}=\max _{p, q}\left[\operatorname{Pr}\left(\pi_{1} \geq \alpha\right)\right]=\max _{p, q}[\operatorname{Pr}((p-$ $\left.\left.c)\left(\theta+\widetilde{\varepsilon}_{1}-a p\right)-k q^{2} \geq \alpha\right)\right]=\operatorname{Pr}\left(\widetilde{\varepsilon}_{1} \geq a p+\left(k q^{2}+\alpha\right) /(p-c)-\theta\right)=$ $1-\vartheta\left(a p+\left(k q^{2}+\alpha\right) /(p-c)-\theta\right)$. Thus, (10) can be simplified as

$$
\begin{aligned}
U^{*} & =\max _{p, q}\left[1-\vartheta\left(a p+\frac{k q^{2}+\alpha}{p-c}-\theta\right)\right] \\
& *[1-\phi(2 \sqrt{a \alpha}+a c-\theta)] .
\end{aligned}
$$

For the survival-seeking case, we have the following proposition.

Proposition 7. Given the uncertainty of DRQ and market shocks, the survival-seeking startup links its price to quality in positive direction: $p^{*}=c+\sqrt{\left(k q^{* 2}+\alpha\right) / a}$. Besides, the startup will reduce the investment on quality if (i) the mean of DRQ increases to a certain level or (ii) the variance of DRQ is increasing.

Proposition 7 first shows an important feature of the survival-seeking startup's operational decisions: it always increases its price in response to the increasing investment on quality. That is, if the startup finds the investment on quality worthy, it will take a risk to increase its price and catch the probability that the market shock is a positive value to the market size. Note that the profit-seeking startup takes this risk to pursue expected profit in the second stage, while the 
survival-seeking startup pursues larger survival chances in the second stage.

Differently from the profit-seeking startup, the survivalseeking startup takes quality investing as one way against the risk. Actually, two competing forces related to quality investing determine the total survival probability. On the one hand, the investment on quality will take up the liquidity and threaten the survival in the first stage. On the other hand, higher quality leads to larger future revenue, which creates more survival chance in the second stage. If the startup has enough cash flow in the first stage, the increasing mean of DRQ encourages the startup to invest in quality. However, as the mean of DRQ increases to a certain level, the startup can easily reach a stable improved market and a relaxed environment in the second stage by small investment on quality. Then, the marginal contribution from quality investing to the survival probability in the second stage will decrease sharply. Thus, the startup decreases its investment to control the risk in the first stage.

Differently from the profit-seeking startup which shows a positive attitude to the risk of DRQ, the survival-seeking startup shows a totally negative attitude. Given a certain quality, as $\sigma^{2}$ increases, the bankruptcy risk in the second stage also increases. Therefore, the startup will reduce its investment on quality to control the risk in the second stage and increase its survival probability in the first stage.

\section{Computational Analysis}

In this section, considering the uncertainty of DRQ and market shocks, a set of numerical analyses are conducted to characterize optimal operational policies for the startup. On the one hand, key parameters $b, \alpha$, and $\sigma$ are continuously varying within reasonable range; on the other hand, potential market size $\theta$, variable cost $c$, and difficulty of quality development $k$ are always taken as common parameters in the overall numerical analysis $(\theta=2, c=0, k=0.5)$. Unless otherwise stated, we set $b=0.75, \alpha=0, \sigma=0$, and $v=1$. At the same time, it is assumed that market shocks follow the normal distribution. A set of representative results are selected and shown in the following content. It should be noted that the obtained conclusions can also be extended to similar results with a wider range of parameters.

5.1. Profit Seeking. Under the profit-seeking objective, the optimization problem under the stochastic environment in (6) can be simplified as follows (developments are described in the proof of Proposition 6):

$$
\begin{aligned}
\pi^{*} & =\max _{p, q \geq 0}\left\{(p-c)(\theta-a p)-k q^{2}\right. \\
& +\frac{(\theta+b q-a c)^{2}+\sigma^{2} q^{2}}{4 a}(1 \\
& \left.-\vartheta\left(a p+\frac{k q^{2}+\alpha}{p-c}-\theta\right)\right) .
\end{aligned}
$$

5.2.1. Mean of DRQ. Impacts of the mean of DRQ on operational decisions and immediate survival probability are also examined. Unlike the profit-seeking case, Figure 5 shows that price setting and quality investing decisions do not change monotonously with $\mathrm{b}$. Instead, these parameters initially increase and then decrease.
As indicated in Proposition 6, the operational decisions in the deterministic case $\left(p_{m}, q_{m}\right)$ can be taken as a benchmark to further study impacts of different parameters.

5.1.1. Mean of DRQ. Figure 2 shows the impacts of the mean of DRQ on operational decisions and the corresponding survival probability. Compared with the deterministic case, Figure 2 shows that the threshold type of the quality investing decision does not exist in the stochastic environment, and operational decisions change continuously with $b$. In detail, as $b$ increases, quality innovation becomes more profitable, which encourages the startup to enhance the investment. If $b \geq 3.53$, operational decisions of price setting and quality investing turn from conservative to aggressive. Consequently, the startup gains more expected profit but bears larger bankruptcy risk.

Besides, Figure 2 shows that the optimal price does not monotonically vary along with an increasing mean of DRQ. In the conservative space, the optimal price initially decreases and then increases. This nonmonotonicity mainly originates from the trade-off between expected profits and the bankruptcy risk. Specifically, when $b<0.6$, improved quality is not attractive that the startup invests little in quality, and the revenue in the first stage is able to support the quality improvement. Therefore, the startup may decrease its price to enable a large market size, against the market shock. As $b$ increases, quality improvement becomes attractive enough, and the startup will increase its price to catch the probability that the market shock is a positive value to the market size and generate short-term cash flow for the quality improvement.

5.1.2. The Uncertainty of DRQ. To support Proposition 5, Figure 3 describes the impact of $\sigma$ on the operational decisions numerically. For a given $b$, the startup will invest in higher quality and set a higher price as $\sigma$ increases. At the same time, the survival probability of the startup decreases.

Actually, $\sigma$ mainly affects the demand realization in the second stage. An increase in $\sigma$ increases the weight of future profits, thereby encouraging aggressive operations.

5.2. Survival Seeking. Based on (12), some important variables $(\mathrm{b}, \alpha, \sigma)$ are also examined based on the comparison between profit-seeking case and survival-seeking case. We use the subscript "pro" to indicate the variable under profit-seeking case, and "sur" to indicate the variable under survival-seeking case. Besides, it is set that $\alpha=4.7$ here unless otherwise stated in order to make the survival probability of the survival-seeking startup around 0.5 . As the price setting strategy changes with the quality investing strategy in positive direction, this subsection mainly focuses on quality investing decision and the consequent survival probability, to make the comparison highly intuitive and focused. 

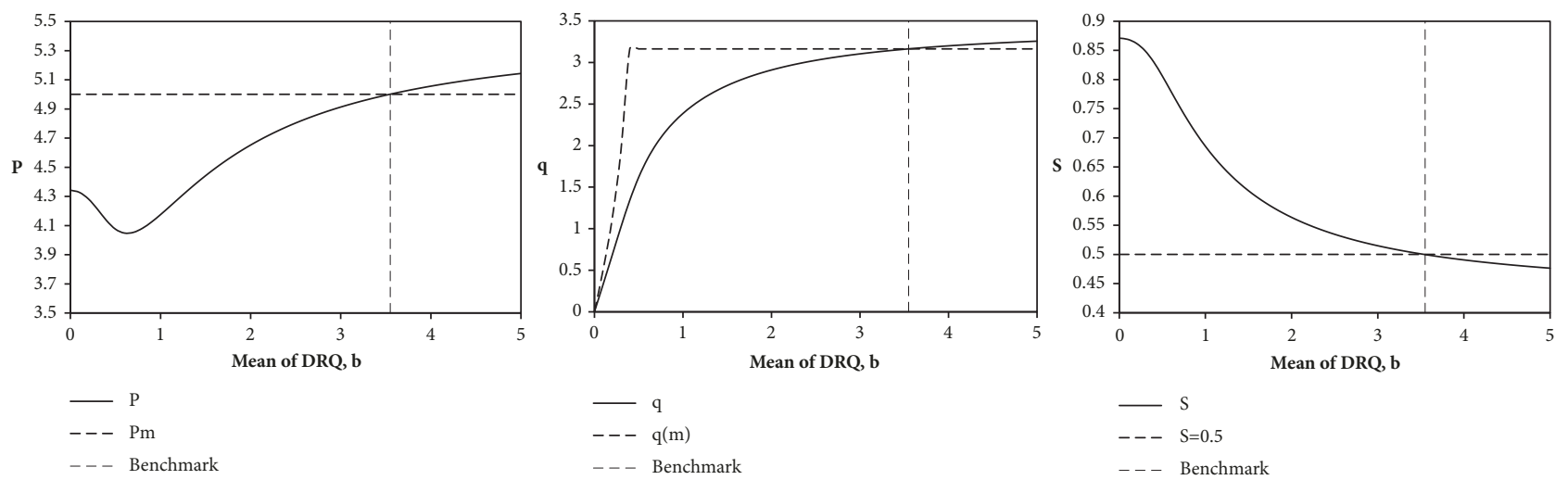

FIgURE 2: Optimal operational decisions and survival probability as functions of $b$.
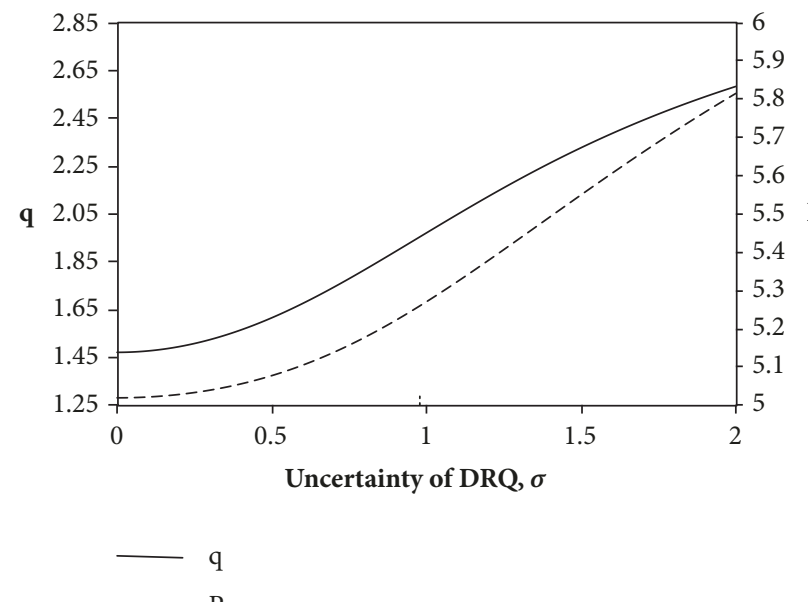

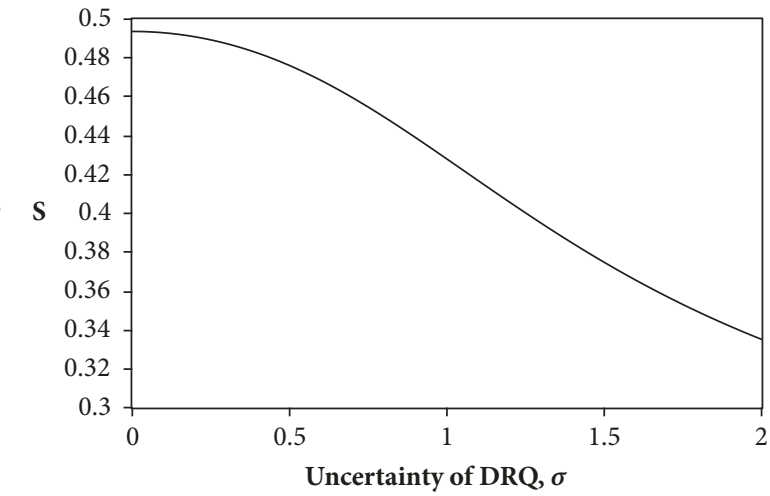

S

FIGURE 3: Optimal operational decisions and survival probability as functions of $\sigma$.

As indicated in Proposition 7, two competing forces related to quality investing determine the total survival probability. On the one hand, as the mean of $\kappa(\epsilon)$ is $b q$, the survival probability in the second stage, $[1-\phi(2 \sqrt{a \alpha}+$ $a c-\theta)$ ], increases along with the investment on quality. This force is dominant when $b$ is small and the total survival probability of the two stages is increasing. Therefore, the startup improves its quality level to make full use of the decreasing quality development cost as shown in Figure 4. On the other hand, the increasing quality also leads to a smaller survival probability in the first stage (the survival probability is $\left.\left[1-\varphi\left(a p+\left(k q^{2}+\alpha\right) /(p-c)-\theta\right)\right]\right)$. When the investment on quality increases to a certain level $(b \approx 1.3$ in Figure 4$)$, the negative influence overweighs the positive influence, thereby driving the startup to reduce its investment on quality and ensure survival. Thus, compared with a profit-seeking startup, a survival-seeking startup is comparatively conservative in its quality investing strategy.

5.2.2. The Uncertainty of $D R Q$. Under the survival-seeking objective, impacts of $\sigma$ on survival probability are shown in Figure 5. According to the assumptions, $q_{m}>0$, there must exist $2 \sqrt{a \alpha}+a c-\theta<0$. Recall that the mean of $\kappa(\epsilon)$ is $b q$ and variance of $\kappa(\epsilon)$ is $v^{2}+q^{2} \sigma^{2}$, so the bankruptcy risk increases along with the increasing $\sigma$, and the startup reduces its investment to control the risk.

5.2.3. Survival Threshold. The survival threshold is the most crucial factor that affects the survival probability of a startup. As indicated in (13), under the profit-seeking objective, increasing survival threshold always makes the expected profit in the second stage lower because the startup has smaller probability of entering into the second stage. Correspondently, the startup will reduce its investment on quality to relieve the severe survival environment.

Under the survival-seeking objective, in contrast, increasing survival threshold makes the survival environment in both stages severer. The investment on quality helps relieve the survival pressure in the second stage; however, this positive impact becomes much smaller when the investment on quality increases to a certain level, and the negative impact of taking up cash flow in the first stage becomes dominant at the same time. Thus, as shown in Figure 6, the investment on quality initially increases and then decreases with the increase of $\alpha$. 
TABLE 1: Impacts of key factors on the quality decision and survival probability of the startup.

\begin{tabular}{lcccc}
\hline \multirow{2}{*}{ Factors (increase) } & \multicolumn{2}{c}{ Profit-seeking } & \multicolumn{2}{c}{ Survival-seeking } \\
& Investment on Quality & Survival Probability & Quality Investment & Survival Probability \\
\hline Mean of DRQ & Increases & Decreases & Increases first, then decreases & Increases \\
Uncertainty of DRQ & Increases & Decreases & Decreases & Decrease \\
Survival threshold & Decreases & Decreases & Increases first, then decreases & Decreases \\
\hline
\end{tabular}
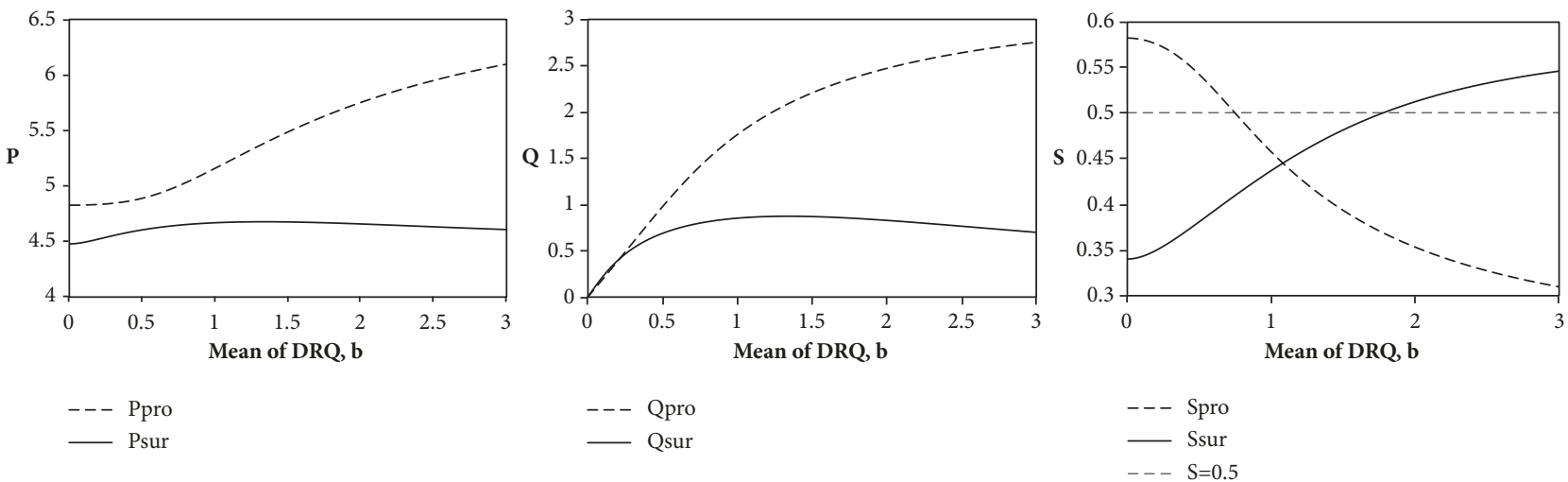

FIGURE 4: Optimal operational decisions and survival probability as functions of $b$.

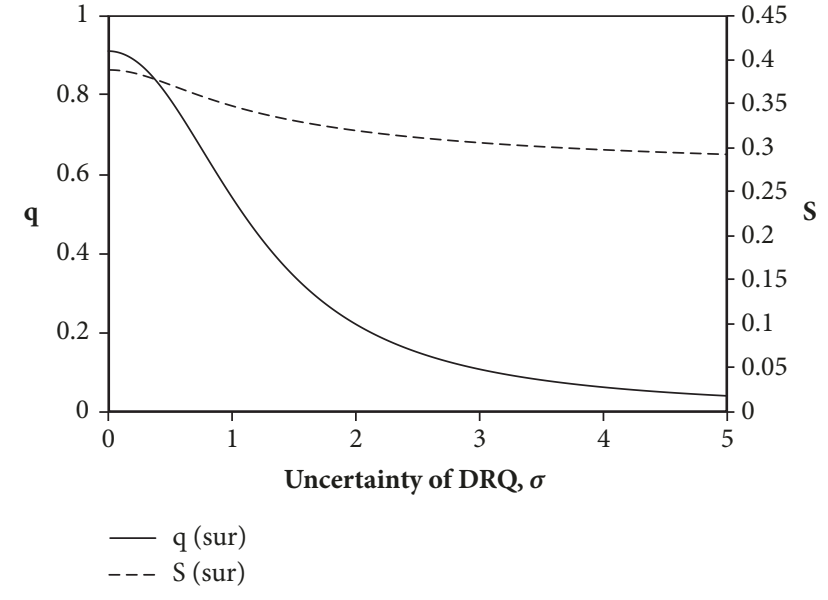

FIGURE 5: Optimal quality as function of $\sigma$.

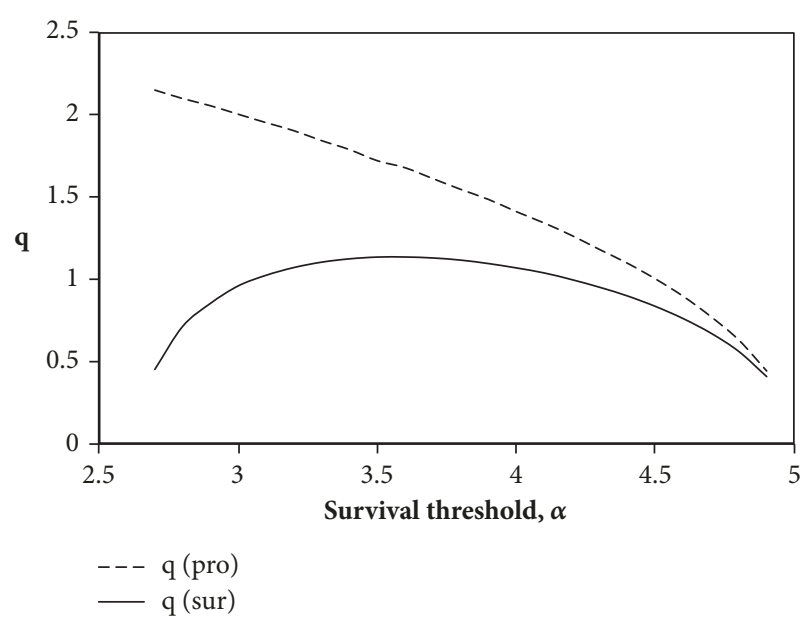

FIGURE 6: Optimal quality as function of $\alpha$.

\section{Conclusions}

Investing in quality for future growth or conserving cash flow in the current stage to avoid bankruptcy is a key trade-off faced by many startups. To extend the discussions regarding this trade-off, this paper uses a two-stage model to analyze how profit- and survival-seeking startups make operational decisions under impacts of DRQ, survival threshold, and market shock.

First, a basic case under deterministic environment is studied and used as a benchmark. Second, the impacts of the uncertainty of DRQ on the operational decisions are examined. Third, besides the uncertainty of DRQ, market shock is also introduced. Some propositions are obtained from the analytical analysis, and computational analysis is made to support these results. Table 1 summarizes impacts of the above-mentioned factors and shows how quality investing strategy and survival probability respond to the increase of each factor in a stochastic environment.

Our analysis provides some important insights that help managers make quality investing decisions:

Firstly, this paper provides a brief yet practical model to describe the price and quality investing decisions and uses the survival probability of the startup (S) as a measurement to represent the bankruptcy risk. Practically, apart from the realistic measures of market size $\theta$, variable cost $c$, and development complexity $k$, managers can assess the demand 
responsiveness to price $(a)$, distribution of DRQ $(\tilde{b})$, and market shock $\left(\widetilde{\varepsilon}_{i}\right)$ through a preliminary market test. Based on these parameters and guides of our research, the startup can quantify its bankruptcy risk exposed in the operational decisions.

Secondly, the startup managers can establish an operational hedge against the bankruptcy risk with the price setting and quality investing decisions. In detail, in the deterministic environment, managers under both objectives can gain the largest profit in the first stage with price $p_{m}$. Then, by the estimation of related parameters, managers decide on the investment on quality $\left(q_{n}\right.$ or $\left.q_{m}\right)$. With the uncertainty of DRQ, managers under the profit-seeking objective may improve its investment properly to pursue the expected profit, while managers under the survival-seeking objective must invest all surplus profit to minimize its risk in the second stage. Considering both the uncertainty of DRQ and market shocks, according to Proposition 6, managers under profitseeking objective may behave conservatively (aggressively) by setting a lower (higher) price and investing in a lower (higher) quality than the deterministic case. In contrast, based on Proposition 7, managers under the survival-seeking objective may make the price setting linked to the investment in positive direction to balance the risks in both stages.

Of course, these hedges are established by some factors, including the DRQ, market shocks, and survival threshold. The individual impact of these factors is quantified in our numerical results, and the startup managers need to take these factors into account when making quality decisions.

Lastly, as mentioned above, operational decisions under different objectives are entirely different. For example, in the stochastic environment, the uncertainty of DRQ encourages the profit-seeking startup to improve the investment on quality, while it discourages the survival-seeking startup. These differences may be primarily attributed to the fact that managers in profit-seeking startups take quality improvement as an opportunity to generate additional profit, while managers of survival-seeking startups take quality improvement as a method for controlling bankruptcy risk. Thus, managers must identify the operational objective before making operational decisions. Managerially, the operational objective of a startup is closely related to its financial standing. If the startup has enough funding for multiple rounds of production and quality investing, managers may make operational decisions to seek profit. However, if the startup bears debt for the investment, managers may make operational decisions to seek survival because their firms are highly exposed to the bankruptcy risk.

This paper also provides some directions for further research. For example, although symmetrical distributions like normal distribution are taken as classic assumptions for the uncertainty of DRQ and market shocks in the literature and used in our research, some other asymmetrical distributions should also be examined because they may affect the monotonicity of functions shown in the figures. Besides, the cost assumption of quality development can also be extended. Based on the classic quadric cost assumption used in our model, startups find it always beneficial to invest in quality. However, these startups may stop their investment if the cost of quality development follows a higher-order form. What is more, competition is also a crucial issue that startups care about in new markets. we can also extend the discussion into competitive market and discuss how competition affects the startups' operational decisions in future research. Finally, even though some anecdotal evidence regarding startups' quality investing decisions has been provided in the introduction and the literature review, further empirical study referring to our numerical results will strengthen the validity of our findings.

\section{Appendix}

Proof of Proposition 4.

$$
\begin{aligned}
& \pi_{2}(q, b)=\max _{p_{2} \geq 0}\left(p_{2}-c\right)\left(\theta-a p_{2}+b q\right) \\
& \text { s.t. }\left(p_{1}-c\right)\left(\theta-a p_{1}\right)-k q^{2} \geq \alpha .
\end{aligned}
$$

We find that $p_{2}^{*}=(\theta+b q+a c) / 2 a$ and $\pi_{2}^{*}(q, b)=$ $(\theta+b q-a c)^{2} / 4 a$. Therefore, (1) is restated as follows: $\pi^{*}=$ $\max _{p_{1}, q \geq 0}\left(p_{1}-c\right)\left(\theta-a p_{1}\right)-k q^{2}+(\theta+b q-a c)^{2} / 4 a$. As the single stage problem is separable in $p_{1}$ and $q$, (1) can be written as $\pi^{*}=\max _{p_{1}, q \geq 0} f\left(p_{1}\right)+g(q)$, where $f\left(p_{1}\right)=$ $\left(p_{1}-c\right)\left(\theta-a p_{1}\right)$ and $g(q)=-k q^{2}+(\theta+b q-a c)^{2} / 4 a$. Given that $f\left(q_{1}\right)$ is concave, this expression is maximized by setting $p_{1}^{*}=(\theta+a c) / 2 a$. Therefore, the upper bound of investment in the first stage is $\pi_{m}-\alpha$, where $\pi_{m}=(\theta-a c)^{2} / 4 a$. However, the discussion on $g(q)$ is complex.

The relationship between $4 a k$ and $b^{2}$ should be analyzed. It can be found that $g(q)$ is concave if $4 a k>b^{2}$, convex if $4 a k<b^{2}$, and linearly increasing otherwise.

If $g(q)$ is concave, this expression obtains the maximized value $g(q)^{*}=k(\theta-a c)^{2} /\left(4 a k-b^{2}\right)$ at $q_{n}$ only when $q_{n}<$ $q_{m}$, which equates to $\left((\theta-a c)^{2} \cdot\left(16 a^{2} k^{2}-12 k a b^{2}+b^{4}\right)\right) /$ $4 a\left(4 a k-b^{2}\right)^{2}-\alpha>0$. By setting $\Delta_{0}=\alpha-\left((\theta-a c)^{2} \cdot\left(16 a^{2} k^{2}\right.\right.$ $\left.\left.-12 k a b^{2}+b^{4}\right)\right) / 4 a\left(4 a k-b^{2}\right)^{2}$, then $\Delta_{0}-\alpha<\Delta_{0} \leq 0$ means that $4 a k>((3+\sqrt{5}) / 2) b^{2}$ or $4 a k<((3-\sqrt{5}) / 2) b^{2}$ (the latter does not exist because $\left.4 a k>b^{2}\right)$. Otherwise, if $\Delta_{0}>$ 0 and $4 a k>b^{2}$, this expression obtains the maximum value $g(q)^{*}=-k q_{m}{ }^{2}+\left(\theta+b q_{m}-a c\right)^{2} / 4 a$ at $q^{*}=q_{m}=$ $\sqrt{(1 / k)\left((\theta-a c)^{2} / 4 a-\alpha\right)}$.

If $g(q)$ is convex, the optimal investment is a boundary solution. The optimal investment amount can be obtained by evaluating the $g(q)$ function for values of 0 and $q_{m}$. Specifically, $g\left(q_{m}\right)=-k q_{m}^{2}+\left(\theta-a c+b q_{m}\right)^{2} / 4 a$ and $g(0)=$ $(\theta-a c)^{2} / 4 a$. Then, the firm invests in $q_{m}$ if $g\left(q_{m}\right)-g(0) \geq 0$. Given that $g\left(q_{m}\right)-g(0)=\left(\left(b^{2}-4 a k\right) q_{m}^{2}+2 b(\theta-a c) q_{m}\right) / 4 a$, $b^{2}>4 a k$ and $\theta-a c>0$, it can be found that investing in $q_{m}$ is always optimal if $g(q)$ is convex.

If $4 a k=b^{2}$, the firm obtains the largest amount $g(q)^{*}=$ $-k q_{m}{ }^{2}+\left(\theta+b q_{m}-a c\right)^{2} / 4 a$ at $q_{m}$. Therefore, Proposition 4 is supported. 
Proof of Proposition 5. Following developments in the proof of Proposition 4 , given the stochastic variable $\widetilde{b}$, the problem in the first stage can be stated as follows:

$$
\begin{aligned}
\pi^{*} & =\max _{p_{1}, q \geq 0} f\left(p_{1}\right)+g(q) \\
\text { s.t. } k q^{2} & \leq f\left(p_{1}\right)-\alpha,
\end{aligned}
$$

where $g(q)=-k q^{2}+\int\left((\theta-a c+\widetilde{b} q)^{2} / 4 a\right) \psi(\widetilde{b}) d \widetilde{b}$ and $f\left(p_{1}\right)=$ $\left(p_{1}-c\right) \cdot\left(\theta-a p_{1}\right)$.

Given that the price and quality investment decisions are partially separable, setting the price remains optimal. The investment threshold and the optimal profit are obtained as follows:

$$
\begin{aligned}
g(q)= & -k q^{2}+\int \frac{(\theta-a c+\widetilde{b} q)^{2}}{4 a} \psi(\widetilde{b}) d \tilde{b} \\
= & -\mathrm{k} q^{2}+\frac{(\theta-a c)^{2}}{4 a}+\frac{2(\theta-a c) q E(\widetilde{b})}{4 a} \\
& +\frac{q^{2} E\left(\widetilde{b}^{2}\right)}{4 a} \\
= & -\mathrm{k} q^{2}+\frac{(\theta-a c)^{2}}{4 a}+\frac{2(\theta-a c) q b}{4 a} \\
& +\frac{q^{2}\left(b^{2}+\sigma^{2}\right)}{4 a} .
\end{aligned}
$$

$g(q)$ is concave if $4 a k>b^{2}+\sigma^{2}$ and convex if $4 a k<b^{2}+\sigma^{2}$; otherwise, $g(q)$ is increasing linearly.

If $g(q)$ is concave, this expression obtains the maximized value $g(q)^{*}=\left(4 a k-\sigma^{2}\right)(\theta-a c)^{2} / 4 a\left(4 a k-b^{2}-\sigma^{2}\right)$ at $q_{u n}=b(\theta-a c) /\left(4 a k-b^{2}-\sigma^{2}\right)$ only when $q_{u n}<q_{m}$, which requires $\left((\theta-a c)^{2} \cdot\left(16 a^{2} k^{2}-12 k a b^{2}-8 a k \sigma^{2}+b^{4}+\right.\right.$ $\left.\left.2 b^{2} \sigma^{2}+\sigma^{2}\right)\right) / 4 a\left(4 a k-b^{2}-\sigma^{2}\right)^{2}>\alpha$. By setting $\Delta_{u b}=$ $\alpha-\left((\theta-a c)^{2} \cdot\left(16 a^{2} k^{2}-12 k a b^{2}-8 a k \sigma^{2}+b^{4}+2 b^{2} \sigma^{2}+\right.\right.$ $\left.\left.\sigma^{4}\right)\right) / 4 a\left(4 a k-b^{2}-\sigma^{2}\right)^{2}$, we find that $\Delta_{u b}-\Delta_{0}=\left(k b^{2} \alpha^{2}\right.$. $\left.\left(8 a k-2 b^{2}-\sigma^{2}\right)\right) /\left(4 a k-b^{2}\right)^{2}\left(4 a k-b^{2}-\sigma^{2}\right)^{2}$. As $4 a k>b^{2}+\sigma^{2}$ in this situation, $\sigma^{2}+2 b^{2}-8 a k<0$. Thus, $\Delta_{u b}>\Delta_{0}$. If $\Delta_{u b}>0$ and $4 a k>b^{2}+\sigma^{2}$, this expression obtains the maximized value $g(q)^{*}=-k q_{m}^{2}+\left((\theta-a c)^{2}+\left(b^{2}+\sigma^{2}\right) q_{m}^{2}+2 b(\theta-\right.$ ac) $\left.q_{m}\right) / 4 a$ at $q^{*}=q_{m}=\sqrt{(1 / k)\left((\theta-a c)^{2} / 4 a-\alpha\right)}$.

If $g(q)$ is convex, the optimal investment is a boundary solution. The optimal investment amount can be obtained by evaluating the $g(q)$ function at the values of 0 and $q_{m}$. Specifically, $g\left(q_{m}\right)=-k q_{m}^{2}+\left((\theta-a c)^{2}+\left(b^{2}+\sigma^{2}\right) q_{m}^{2}+2 b(\theta-\right.$ ac) $\left.q_{m}\right) / 4 a$ and $g(0)=(\theta-a c)^{2} / 4 a$. The startup invests all excess profits $\left(\pi_{m}-\alpha\right)$ if $g\left(q_{m}\right)-g(0) \geq 0$. By evaluating this condition, we obtain $g\left(q_{m}\right)-g(0)=\left(\left(b^{2}+\sigma^{2}-4 a k\right) q_{m}^{2}+\right.$ $\left.2 b(\theta-a c) q_{m}\right) / 4 a$. Given that $b^{2}+\sigma^{2}>4 a k$ and $\theta-a c>0$, investing in $q_{m}$ is always optimal if $g(q)$ is convex.

If $4 a k=b^{2}+\sigma^{2}$, the startup obtains the largest amount $g(q)^{*}=-k q_{m}{ }^{2}+\left((\theta-a c)^{2}+\left(b^{2}+\sigma^{2}\right) q_{m}^{2}+2 b(\theta-a c) q_{m}\right) / 4 a$ at $q_{m}$.
Proof of Proposition 6 . Note that $\tilde{b}$ is realized at the end of the first period. Therefore, when deciding $p_{2}$ at the beginning of the second period, the startup observes the realized $\widetilde{b}$. Therefore, the startup solves the following problem in the second period if it survives in the first period (i.e., $\pi_{1}\left(\widetilde{\varepsilon}_{1}, \widetilde{b}\right) \geq$ $\alpha): \pi_{2}\left(\widetilde{\varepsilon}_{2}\right)=\left(p_{2}-c\right)\left(\theta+\widetilde{\varepsilon}_{2}-a p_{2}+\widetilde{b} q\right)$. Given that $E\left(\widetilde{\varepsilon}_{2}\right)=0$, the problem turns to $E_{\widetilde{\varepsilon}_{2}} \pi_{2}=\left(p_{2}-c\right)\left(\theta-a p_{2}+\tilde{b} q\right)$, and the optimal price in the second period is $p_{2}=(\theta+a c+$ $\tilde{b} q) / 2 a . p_{2}$ only depends on the realization of the stochastic variable $\widetilde{b}$. Assuming that $p_{2} \geq 0$, expected profits of the startup are computed as $(\theta-a c+\tilde{b} q)^{2} / 4 a$. By substituting this equation into the first stage, the overall profit is computed as $\pi^{*}=\max _{p_{1}, q \geq 0} E_{\widetilde{\varepsilon}_{1}}\left\{\left(p_{1}-c\right)\left(\theta+\widetilde{\varepsilon}_{1}-a p_{1}\right)-k q^{2}\right\}+E_{\widetilde{b}}\{(\theta$ $\left.+\widetilde{b} q-a c)^{2} / 4 a \mid \pi_{1}\left(\widetilde{\varepsilon}_{1}, \widetilde{b}\right) \geq \alpha\right\}$. Hereafter, $p_{1}$ in the reduced model is denoted by $p$, and the problem is simplified as

$$
\begin{aligned}
\pi^{*} & =\max _{p, q \geq 0}\left\{E_{\widetilde{\varepsilon}_{1}}\left\{(p-c)\left(\theta+\widetilde{\varepsilon}_{1}-a p\right)-k q^{2}\right\}\right. \\
& \left.+\int_{G} \int_{0}^{\infty} \frac{(\theta+\widetilde{b} q-a c)^{2}}{4 a} \psi(\widetilde{b}) w\left(\widetilde{\varepsilon}_{1}\right) d \widetilde{b} d \widetilde{\varepsilon}_{1}\right\} \\
\pi^{*} & =\max _{p, q \geq 0}\left\{(p-c)(\theta-a p)-k q^{2}\right. \\
& \left.+\int_{G} \int_{0}^{\infty} \frac{(\theta+\tilde{b} q-a c)^{2}}{4 a} \psi(\widetilde{b}) w\left(\widetilde{\varepsilon}_{1}\right) d \widetilde{b} d \widetilde{\varepsilon}_{1}\right\} \\
\pi^{*} & =\max _{p, q \geq 0}\left\{(p-c)(\theta-a p)-k q^{2}\right. \\
& +\frac{(\theta+b q-a c)^{2}+\sigma^{2} q^{2}}{4 a}(1 \\
& \left.\left.-\vartheta\left(a p+\frac{k q^{2}+\alpha}{p-c}-\theta\right)\right)\right\}
\end{aligned}
$$

where $G=\left\{\theta \mid \pi_{1}\left(\widetilde{\varepsilon}_{1}\right) \geq \alpha\right\}$. At the optimality, the following equation holds: $\partial \pi^{*} / \partial p=\theta+a c-2 a p-((\theta+$ $\left.b q-a c)^{2}+\sigma^{2}\right) / 4 a \cdot w\left(a p+\left(k q^{2}+\alpha\right) /(p-c)-\theta\right)\left(a-\left(k q^{2}+\right.\right.$ $\left.\alpha) /(p-c)^{2}\right)=0$.

Note that $\left(\partial \pi^{*} / \partial p\right)_{p \rightarrow c}>0,\left(\partial \pi^{*} / \partial p\right)_{p \rightarrow \infty}<0, \partial \pi^{*} / \partial p$ is continuous, and $q_{m}=\sqrt{(1 / k)\left((\theta-a c)^{2} / 4 a-\alpha\right)}$, so $p^{*}>$ $p_{m} \Longleftrightarrow a-\left(k\left(q^{*}\right)^{2}+\alpha\right) /\left(p^{*}-c\right)^{2}>0 \Longleftrightarrow q^{*}>q_{m}$, and $p^{*}<p_{m} \Longleftrightarrow a-\left(k\left(q^{*}\right)^{2}+\alpha\right) /\left(p^{*}-c\right)^{2}<0 \Longleftrightarrow q^{*}<q_{m}$.

Proof of Proposition 7.

$$
\begin{aligned}
U^{*} & =\max _{p, q}\left[1-\vartheta\left(a p+\frac{k q^{2}+\alpha}{p-c}-\theta\right)\right] \\
& *[1-\phi(2 \sqrt{a \alpha}+a c-\theta)] .
\end{aligned}
$$


At the optimality, the following equation holds: $\partial U^{*} / \partial p=$ $[1-\phi(2 \sqrt{a \alpha}+a c-\theta)] *\left(-w\left(a p+\left(k q^{2}+\alpha\right) /(p-c)-\theta\right)\right) *$ $\left(a-\left(k q^{2}+\alpha\right) /(p-c)^{2}\right)=0$. Thus, $p^{*}=c+\sqrt{\left(k q^{* 2}+\alpha\right) / a}$, and $\left[1-\vartheta\left(a p+\left(k q^{2}+\alpha\right) /(p-c)-\theta\right)\right] \Longleftrightarrow[1-\vartheta(a c+$ $\left.\left.2 \sqrt{a\left(k q^{* 2}+\alpha\right)}-\theta\right)\right]$.

As $q$ increases, $\left[1-\vartheta\left(a c+2 \sqrt{a\left(k q^{* 2}+\alpha\right)}-\theta\right)\right]$ decreases, and $[1-\phi(2 \sqrt{a \alpha}+a c-\theta)]$ may increase because the mean of cumulative distribution $\phi(\epsilon)$ is $b q$. However, as $b \longrightarrow+\infty$, if $q$ increases, the positive effect from $[1-\phi(2 \sqrt{a \alpha}+a c-\theta)]$ must be extremely small, and the negative effect from $[1-\vartheta(a c+$ $\left.\left.2 \sqrt{a\left(k q^{* 2}+\alpha\right)}-\theta\right)\right]$ will be dominant. Thus, the startup will reduce its investment on quality when $b$ increases to a certain level.

Additionally, note that $q_{m}>0$ requires $2 \sqrt{a \alpha}+a c-\theta>0$. It can be known that the survival probability in the second stage is larger than 0.5 , and the mean bq is on the right side of $(2 \sqrt{a \alpha}+a c-\theta)$. Therefore, $U^{*}$ is decreasing with $\sigma^{2}$ because the variance of cumulative distribution $\phi(\epsilon)$ is $v^{2}+q^{2} \sigma^{2}$. Accordingly, a decrease of $q$ will not only weaken the negative effect from the decreasing $\sigma^{2}$ on the second stage, but also increase the survival probability in the first stage.

\section{Data Availability}

We carried out the analysis mainly by analytical model and did not use any data for support.

\section{Conflicts of Interest}

The authors declare that they have no conflicts of interest.

\section{Acknowledgments}

This research was supported by the National Natural Science Foundation of China (Grant 71473193).

\section{References}

[1] Z. J. Acs and C. Armington, Endogenous growth and entrepreneurial activity in cities, Center for Economic Studies, Bureau of the Census, Washington, DC, USA, 2003.

[2] S. Gifford, "Risk and uncertainty," in Handbook of Entrepreneurship Research, J. Z. Acs and D. B. Audretsch, Eds., pp. 37-53, Kluwer Academic Publishers, Boston, USA, 2003.

[3] A. N. Berger and G. F. Udell, "Small business debt and finance," in Handbook of Entrepreneurship Research, Z. J. Acs and D. B. Audretsch, Eds., pp. 299-328, Kluwer Academic Publishers, Boston, USA, 2003.

[4] G. C. Reid, "Complex actions and simple outcomes: how new entrepreneurs stay in business," Small Business Economics, vol. 13, no. 4, pp. 303-315, 1999.

[5] F. Tanräsever, S. S. Erzurumlu, and N. Joglekar, "Production, process investment, and the survival of debt-financed startup firms," Production Engineering Research and Development, vol. 21, no. 4, pp. 637-652, 2012.

[6] R. D. Banker, I. Khosla, and K. K. Sinha, "Quality and competition,” Management Science, vol. 44, no. 9, pp. 1179-1192, 1998.
[7] A. V. Bhidé, The Origin and Evolution of New Businesses, Oxford University Press, 2003.

[8] C. B. Insights, “The top 20 reasons startups fail," vol. 7, 2014, https://www.cbinsights.com/blog/startup-failure-reasons-top/.

[9] C. Thompson, How Tesla emerged from the brink of bankruptcy to become America's coolest car company, 2017, http://www .businessinsider.com/most-important-moments-tesla-history2017-2/\#july-2003-tesla-motors-was-founded-by-a-group-ofsilicon-valley-engineers-1.

[10] J. Urbina and M. Guillén, "An application of capital allocation principles to operational risk and the cost of fraud," Expert Systems with Applications, vol. 41, no. 16, pp. 7023-7031, 2014.

[11] K. S. Kim, T. L. Knotts, and S. C. Jones, "Characterizing viability of small manufacturing enterprises (SME) in the market," Expert Systems with Applications, vol. 34, no. 1, pp. 128-134, 2008.

[12] E. Cefis and O. Marsili, "A matter of life and death: Innovation and firm survival," Industrial and Corporate Change, vol. 14, no. 6, pp. 1167-1192, 2005.

[13] E. Cefis and O. Marsili, "Survivor: The role of innovation in firms' survival," Research Policy, vol. 35, no. 5, pp. 626-641, 2006.

[14] P. Criscuolo, N. Nicolaou, and A. Salter, “The elixir (or burden) of youth? Exploring differences in innovation between start-ups and established firms," Research Policy, vol. 41, no. 2, pp. 319-333, 2012.

[15] S. A. Shane, The Illusions of Entrepreneurship: The Costly Myths That Entrepreneurs, Investors, and Policy Makers Live by, Yale University Press, 2010.

[16] K. S. Moorthy, "Product and price competition in a duopoly," Marketing Science, vol. 7, no. 2, pp. 141-168, 1988.

[17] R. Narasimhan and D. Méndez, "Strategic aspects of quality: A theoretical analysis," Production Engineering Research and Development, vol. 10, no. 4, pp. 514-526, 2001.

[18] V. Krishnan and K. T. Ulrich, "Product development decisions: A review of the literature," Management Science, vol. 47, pp. 1-21, 2001.

[19] G. Xie, W. Yue, S. Wang, and K. K. Lai, "Quality investment and price decision in a risk-averse supply chain," European Journal of Operational Research, vol. 214, no. 2, pp. 403-410, 2011.

[20] Ö. Karaer and F. Erhun, "Quality and entry deterrence," European Journal of Operational Research, vol. 240, no. 1, pp. 292303, 2015.

[21] H. Zhang and D. Hong, "Manufacturer's R and D investment strategy and pricing decisions in a decentralized supply chain," Discrete Dynamics in Nature and Society, 2017.

[22] J. C. Li, J. H. Lu, Q. L. Wang, and C. Li, "Quality and pricing decisions in a two-echelon supply chain with nash bargaining fairness concerns," Discrete Dynamics in Nature and Society, 2018.

[23] J. Shi, R. Y. K. Fung, and J. Guo, "Optimal ordering and pricing policies for seasonal products: impacts of demand uncertainty and capital constraint," Discrete Dynamics in Nature and Society, vol. 2016, 2016.

[24] J. E. Stiglitz and B. C. Greenwald, "Asymmetric information and the new theory of the firm: Financial constraints and risk behavior," American Economic Review, vol. 80, no. 2, pp. 160$165,1990$.

[25] J. A. Buzacott and R. Q. Zhang, "Inventory management with asset-based financing," Management Science, vol. 50, no. 9, pp. 1274-1292, 2004. 
[26] N. R. Joglekar and M. Lévesque, "Marketing, R\&D, and startup valuation," IEEE Transactions on Engineering Management, vol. 56, no. 2, pp. 229-242, 2009.

[27] R. Swinney, G. P. Cachon, and S. Netessine, "Capacity investment timing by start-ups and established firms in new markets," Management Science, vol. 57, no. 4, pp. 763-777, 2011.

[28] V. Babich, "Dealing with supplier bankruptcies: Costs and benefits of financial subsidies," in Proceedings of the 2007 International Conference on Manufacturing and Service Operations Management, 2007.

[29] T. W. Archibald, L. C. Thomas, J. M. Betts, and R. B. Johnston, "Should start-up companies be cautious? Inventory policies which maximise survival probabilities," Management Science, vol. 48, no. 9, pp. 1161-1174, 2002.

[30] M. M. Wei, T. Yao, B. Jiang, and S. T. Young, "Profit seeking vs. survival seeking: An analytical study of supplier's behavior and buyer's subsidy strategy," Production Engineering Research and Development, vol. 22, no. 2, pp. 269-282, 2013.

[31] B. Xia, J. Guo, and R. Y. K. Fung, "Quality investment timing by the startup and the established firm," Managerial and Decision Economics, vol. 39, no. 3, pp. 275-284, 2018.

[32] M. Lévesque, X. Zhao, and J. Bian, "Competitive interplay of production decisions: rivalry between established and startup firms," IEEE Transactions on Engineering Management, vol. 65, no. 1, pp. 85-98, 2018.

[33] J. Chen, L. Liang, and F. Yang, "Cooperative quality investment in outsourcing," International Journal of Production Economics, vol. 162, pp. 174-191, 2015.

[34] P. Ma, H. Wang, and J. Shang, "Contract design for two-stage supply chain coordination: integrating manufacturer-quality and retailer-marketing efforts," International Journal of Production Economics, vol. 146, no. 2, pp. 745-755, 2013.

[35] W. Zhu and Y. He, "Green product design in supply chains under competition," European Journal of Operational Research, vol. 258, no. 1, pp. 165-180, 2017. 


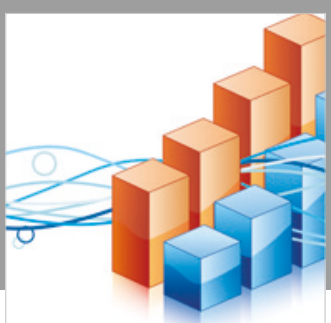

Advances in

Operations Research

\section{-n-m}
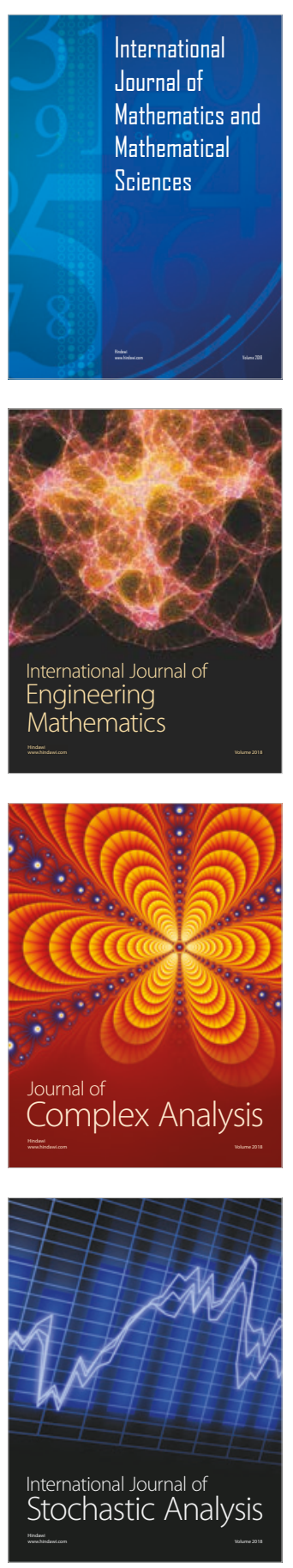
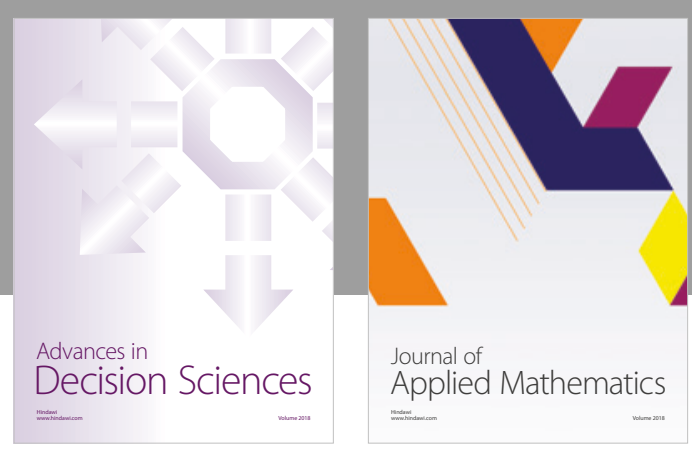

Journal of

Applied Mathematics
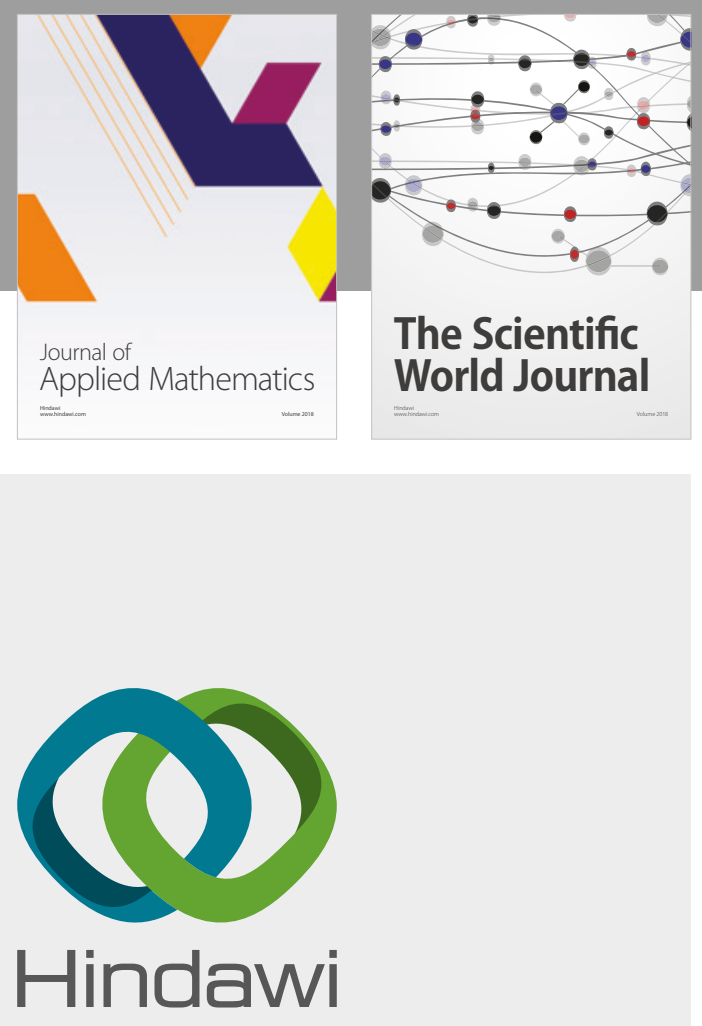

Submit your manuscripts at

www.hindawi.com

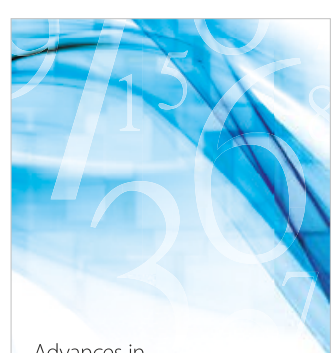

Advances in
Numerical Analysis
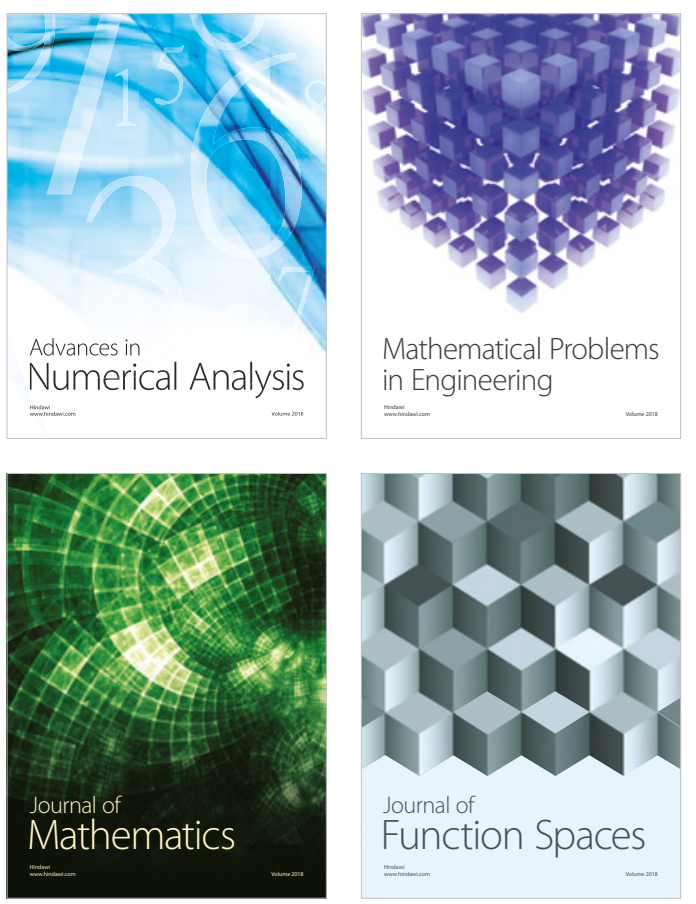

Mathematical Problems in Engineering

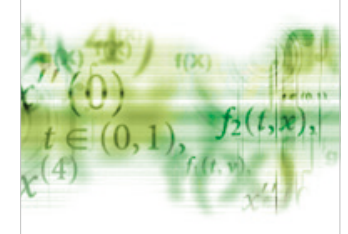

International Journal of

Differential Equations

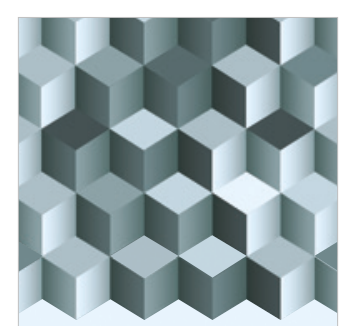

Journal of

Function Spaces

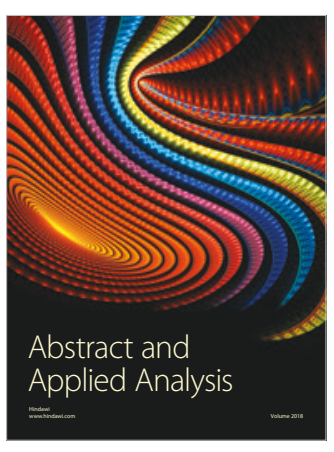

The Scientific

World Journal

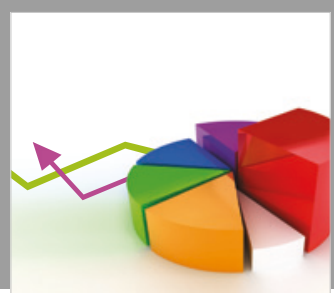

Journal of

Probability and Statistics
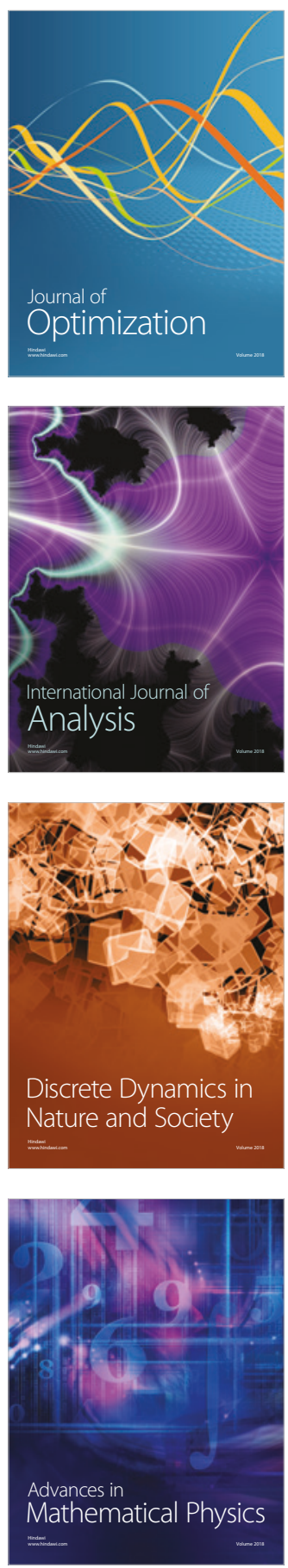